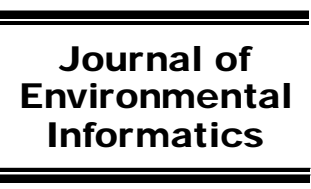

www.iseis.org/jei

\title{
ASOC: A Novel Agent-Based Simulation-Optimization Coupling Approach-Algorithm and Application in Offshore Oil Spill Responses
}

\author{
P. Li, B. Chen", Z. L. Li, and L. Jing \\ Northern Region Persistent Organic Pollution Control (NRPOP) Laboratory, Faculty of Engineering and Applied Science, Memorial University \\ of Newfoundland, St. John's, NL A1B 3X5, Canada
}

Received 3 April 2015; revised 20 November 2015; accepted 26 November 2015; published online 23 December 2016

\begin{abstract}
The efficiency of offshore oil spill response not only relies on an efficaciously global decision/planning in devices combination and allocation, but also depends on the timely control for response devices (e.g., skimmers and booms). However, few studies have reported on such decision framework with a timely integration of global planning and operation control to support offshore oil spill response. This study developed an agent-based simulation-optimization approach to provide sound decisions for device combination and allocation during offshore oil spill recovery in a fast, dynamic and cost-efficient manner under uncertain conditions. Meanwhile, the proposed approach aimed at providing operation control schemes for different devices, reflecting the site conditions, and correspondingly adjusting the global planning in a real-time manner. Such functions would be extremely helpful in the harsh environments prevailing in offshore Newfoundland. In the case study, the developed approach was applied to determine the allocation of 3 responding vessels in collecting spilled oil at 7 locations. The routes of the responding vessels for response operation were optimized and reflected by the principle agent-based programming. Furthermore, several oil weathering processes (e.g., evaporation and dispersion) were also taken into account in the optimization. The modeling results indicated that a minimal timeframe of 21 hours was needed for vessel allocation and recovery operation, leading to an oil recovery rate of $90 \%$. By taking evaporation and dispersion into account, the optimal time window was 18 hours, leading to an oil recovery rate of $75 \%$, an evaporation rate of $12 \%$, and a dispersion rate of $3 \%$. The proposed approach can timely and effectively support the optimal allocation of devices, the control of operation, and the real-time adjustment of global decision making for oil recovery under dynamic conditions.
\end{abstract}

Keywords: oil spill response, optimization, uncertainty, dynamic, agent-based programming

\section{Introduction}

During offshore oil spill response, strong interactions exist among the response devices (e.g., vessels, recovery devices, storage barge), responders, decision makers, etc. These interactions dynamically occur during the whole process of an offshore oil spill response. It may lead to unreliability or compromise of the response actions if these interactions are not considered in the global optimization. In order to address these interactions, an agent-based model is introduced.

Offshore oil spill is a common type of coastal and marine pollution. It is defined as an accident release or discharge of petroleum hydrocarbons due to human operations or natural disasters. Tankers, offshore platforms and drilling rigs, as well as subsea piping lines are among the most common sources of oil spills. Various types of hydrocarbon contaminants can be involved in an oil spill accident, including crude oil, refined

\footnotetext{
${ }^{*}$ Corresponding author. Tel.: +1 709 8648958; fax: +1 7098644042.

E-mail address: bchen@mun.ca (B. Chen).
}

ISSN: 1726-2135 print/1684-8799 online

(C) 2016 ISEIS All rights reserved. doi: 10.3808/jei.201600354 oil products, heavier fuels, and waste oil, etc. (Jing et al., 2012; Li et al., 2012). In history, oil spills have caused significant damage to the marine environment and local ecosystems. Given that specific situations can be vastly distinuished from each other, different strategies and technologies were deployed during the clean-up processes. Both spills have led to tremendous economic losses and durable social/environ mental impacts, for which, the inefficient decision support systems during the emergency response were one of the important issues (Yin et al., 1999; Picou, 2009; Chen et al., 2010; Atlas and Hazen, 2011; Griggs, 2011; Gill et al., 2012; Ben-Awuah et al., 2015; Nourani et al., 2015; Rege et al., 2015).

After offshore oil spill, various transformation processes will occur and many of these processes are relating to the behavior of the oil. A series of processes regarding the physical and chemical properties of the oil occur right after the oil spill, which are the weathering processes with the most important processes of evaporation and emulsification. The other important processes are relating to the oil movement in offshore (Fingas, 2010). Usually the weathering and movement processes can strongly interact with each other in the offshore environment. These processes mainly include evaporation, dissolution, emulsification, dispersion, biodegradation, sprea- 
ding, photolysis, advection, diffusion, sedimentation, and the interaction of oil slick with the shoreline (Gundlach and Hayes, 1978; Korotenko et al., 2000). Generally, the oil properties, hydrodynamics, meteorological and environmental conditions play important roles in the physical, chemical and biological processes for the spilled oil transport and fate (Reed et al., 1999; Brebbia, 2001; Cheng et al., 2002).

Accompanied by the booming of offshore oil production and transportation, particularly during the recent few decades, prompt response to oil spills has been recognized as a critical issue. Growing research efforts have been undertaken into developing an effective and efficient tool for oil spill emergency decision support systems. For example, Baruque et al. (2010) applied a Case-Based Reasoning (CBR) methodology in forecasting the presence and trajectory of oil slicks in open sea by analyzing the previously solved problems, thus to shorten the time needed for decision making. In another study, Krohling and Campanharo (2011) combined fuzzy theory with the concept of Technology for Order Preference by Similarity to Ideal Solution (TOPSIS) in offshore oil spill decision making, where multi-scenarios can be simulated using different combat strategies to establish contingency plans based on the prioritized criteria. In addition, Kokkonen et al. (2010) applied a mapping tool to integrate both geological and ecological data for boom allocation under dynamic local sensitivities to potential oil spills.

In addition to oil spill simulation, optimization is also desired to provide decision support under changing environmental conditions (Huang et al., 1996; Huang and Cao, 2011; Gong et al., 2016). Zhong and You (2011) developed a multi objecttive linear model for operational cleanup schedules and coastal protection plans during an oil spill event. Sheu et al. (2005) used a fuzzy clustering technique for optimizing resource allocation during disasters other than oil spills. Verma et al. (2013) formulated a two-stage stochastic programming to optimize the allocation of oil spill facilities along the southern coast of Newfoundland. Besides, many studies also considered to integrate optimization with simulation, particularly under dynamic situations. For example, You and Leyffer (2011) took into account the time-dependent factors regarding oil properties, hydrodynamics, and weather conditions while optimizing the response plans. Li et al. (2014) introduced uncertainties into the decision making processes during oil spills, by developing a Monte Carlo based dynamic mixed integer nonlinear programming for devices allocation optimization.

Challenges still remain in reflecting the highly dynamical interactions between different sectors during optimization modelling for offshore oil spill response (Lv et al., 2010; Huang et al., 2016). Such interactions can be simulated by an agentbased simulation approach. According to Wooldridge and Jennings (1995), an agent can be defined as "a software or hardware entity that is situated in some environment, and is capable of performing autonomous actions in that environment in order to meet its design objectives". Thus, an agent can be characterized by its autonomy, social ability, reactive and pro- tective behavior. The autonomy can allow an agent indpendently completing any complex tasks (Rahmani and Zaghami, 2015). The social ability can drive an agent to interact and negotiate with the other agents to achieve its task, and the system goal can be achieved based on the interaction and negoation from all agents. The reactive behavior of an agent can help dynamically perceive and respond to the changing environment, while the proactive behavior can make an agent dynamically change its behavior according to the change of environment to achieve its goal (Tan et al., 2015). Some other properties of agents include mobility, temporal continuity, collaborative behavior, etc. (Liu et al., 2002). Nevertheless, challenges still remain in the integration of agentbased simulation and the optimization approaches (Cai et al., 2009).

Despite that dynamic conditions have been considered for previous studies, harsh environments tend to make emergency response to oil spills even more challenging by changing the fate and properties of oil dramatically within short period of time, which will inevitably impede the recovery and cleanup processes unless timely updates of operational schedules are made (Brandvik et al., 2006; Bjerkemo, 2011). Few studies up to date have been carried out specifically to address this issue. Therefore, a real-time decision support systems taking into account the restrictions of devices and logistical efficiency is urgently desired.

To fill this gap, agent-based modeling (ABM) is hereby proposed to render a certain degree of autonomous characteristic to the system, thus to achieve a better simulation of the process and make the optimization of the operational schedule more practical. This study aims at developing an agent-based model, which couples both simulation and optimization under dynamic conditions, to provide a real-time decision support for devices allocation and operation control during offshore oil spill response. Firstly, the algorithm of agent-based simulation-optimization (ASO) is provided. Accordingly, a hypocritical case of response devices allocation in offshore oil spill response is conducted. The results of case study is then analyzed and discussed followed with conclusion. The outcomes of the study is expected to facilitate a more effective and efficient tool for emergency oil spill response under highly dynamic conditions.

\section{Agent-Based Simulation-Optimization}

\subsection{Simulation-Based Dynamic Mixed Integer Nonlinear Programming}

Consider a linear program as follows:

Min $f=C_{j} X_{j}$

s.t.

$\sum_{j=1}^{n} A_{i j} X_{j} \leq B_{i}, \quad i=1, \cdots, m$

$X_{j} \geq 0$ 
where $C \in\{R\}^{1 \times n}$ is the matrix of coefficients of the objective function; and $A_{i j} \in\{R\}^{m \times n}$ as well as $B_{i} \in\{R\}^{m \times 1}$ are matrices of variable constraint coefficients.

When $C_{j}$ are not just constants but also functions linking with some other parameters:

$C_{j}=g_{j}(y)$

where $g_{j}(y)$ are the functions showing the relations between the coefficients $C$ and parameters $y$, leading to a simulationbased optimization model as follows:

$$
\begin{aligned}
& \operatorname{Min} f=g_{j}(y) X_{j} \\
& \text { s.t. } \\
& \sum_{j=1}^{n} A_{i j} X_{j} \leq B_{i}, \quad i=1, \cdots, m \\
& X_{j} \geq 0
\end{aligned}
$$

Equation 3 will be a simple linear model and can be solved by linear programming if $g_{j}(y)$ is independent from the decision variables $\left(X_{j}\right)$. However, when $g_{j}(y)$ are dependent on the decision variables, the model becomes non-linear. Especially when $g_{j}(y)$ are dynamically relating with the decision variables (usually with time series), the model becomes dynamic and non-linear, and cannot be easily solved:

$$
\operatorname{Min} f_{t}=\psi\left(f_{t-1}\left(g_{j}\left(y_{t-1}\right) X_{j}\right), g_{j}\left(y_{t}\right) X_{j}\right)
$$

s.t.

$$
\begin{aligned}
& \sum_{j=1}^{n} A_{i j} X_{j} \leq B_{i}, \quad i=1, \cdots, m \\
& X_{j} \geq 0
\end{aligned}
$$

where $t$ and $t-1$ are time indicators in a time series, and the $f_{t}=\psi\left(f_{t-1} g_{j}\left(y_{t-1}\right) X_{j}, g_{j}\left(y_{t}\right) X_{j}\right)$ represents relations between the status from the previous and the current stages. For a single stage or globally continuous problem, Equation 4 can be converted as follows:

$$
\operatorname{Min} f=\int_{0}^{T} \psi\left(f_{t-1}\left(g_{j}\left(y_{t-1}\right) X_{j}\right), g_{j}\left(y_{t}\right) X_{j}\right) d t
$$

s.t.

$$
\begin{aligned}
& \sum_{j=1}^{n} A_{i j} X_{j} \leq B_{i}, \quad i=1, \cdots, m \\
& X_{j} \geq 0
\end{aligned}
$$

It will be more convenient to break the time series into certain stages based on a controllable time interval, leading to a simulation-based dynamic mixed integer nonlinear programming (DMINP) as follows:

$$
\operatorname{Min} f=\sum_{s=1}^{N}\left[\int_{0}^{t_{s}} \psi\left(f_{s-1}\left(g_{j}\left(y_{t-1}\right) X_{j}\right), g_{j}\left(y_{t}\right) X_{j}, t\right) d t\right]
$$

$$
\begin{aligned}
& \text { s.t. } \\
& \sum_{j=1}^{n} A_{i j} X_{j} \leq B_{i}, \quad i=1, \cdots, m \\
& X_{j} \geq 0
\end{aligned}
$$

where $t_{s}$ is the time interval in the stage $s$. In some cases, $g_{j}(y)$ in the same stage can be assumed to be constant and Equation 6 can be correspondingly converted to:

$$
\begin{aligned}
& \text { Min } f=\sum_{s=1}^{N} \psi\left(f_{s-1}\left(g_{j}\left(y_{t-1}\right) X_{j} t_{s-1}\right), g_{j}\left(y_{t}\right) X_{j} t_{s}\right) \\
& \text { s.t. } \\
& \sum_{j=1}^{n} A_{i j} X_{j} \leq B_{i}, \quad i=1, \cdots, m \\
& X_{j} \geq 0
\end{aligned}
$$

\subsection{Oil Recovery Simulation}

In offshore oil spill recovery, the net oil recovery rate $\left(O R R_{n}\right.$, defined as the amount of recovered oil per hour) of skimmer is usually determined by slick thickness $(S T)$. The function between $O R R_{n}$ and $S T$ is described as follows:

$O R R_{n}=a \times S T^{2}+b \times S T$

where $a$ and $b$ are empirical coefficients obtained from experimental tests. Correspondingly, the objective function of the offshore oil spill recovery problem by skimmer can be expressed as follows:

$\operatorname{Max} V=\int_{0}^{t} S K_{i} \times O R R_{n i} d t$

where $V$ is the volume of recovered oil, $t$ is the operational time, $S K_{i}$ are the numbers of skimmer type $i$, and $O R R_{n i}$ are the recovery rates of the corresponding skimmer.

As $O R R_{n i}$ are dynamically related with the objective value $(V)$, the problem becomes dynamic and non-linear, and cannot be easily solved. It will be more convenient to break the time series into multiple stages based on a controllable time interval defined as the minimal time required for shifting one operational condition to another. The duration of a stage is usually determined by the time for device deployment and allocation, resource arrangement, etc. This leads to a multiple-stage simulation based nonlinear programming as follows:

$\operatorname{Max} V=\sum_{s=1}^{N} S K_{i} \times O R R_{n i s}$

where $N$ is the length of an operational period, $s$ is the number of operational stages, $O R R_{n i s}$ are net oil recovery rates for $S K_{i}$ at stage $s$, which is calculated by the slick thickness or the collected oil from the stage $s-1$ : 
$O R R_{n i s}=f_{O R R_{n i}}\left(S T_{s-1}\right)=f_{O R R_{n i}}\left(\frac{V_{0}-\sum_{h=1}^{s-1} V_{h}}{A}\right)$

where $V_{0}$ is the initial volume of spilled oil, $A$ is the area of the spilled oil, and $h$ is the stage index.

\subsection{Weathering Simulation}

In real-world practices, oil recovery is significantly affectted by the weathering processes such as spreading and drift, evaporation, natural dispersion, emulsification, biodegradetion, etc. (Fingas, 2010). In a case that spilled oil is boomed and the recovery is required to be done within a short period, evaporation, dispersion, and emulsification may play important roles in oil weathering. Therefore, these processes will also be taken into account in the multiple-stage simulation based nonlinear programming. According to Fingas (20$11)$, the empirical equation of evaporation for oil is as follows:

$F E=\frac{c+d \times(T-273.15) \times \operatorname{Ln}(t)}{100}$

where $c$ and $d$ are equation parameters for specific oil, $F E$ is the evaporation rate $\left(\mathrm{m}^{3} /\right.$ hour $\cdot \mathrm{m}^{3}$ of oil), $T$ is temperature $(\mathrm{K})$, and $t$ is time ( $\mathrm{min})$.

Emulsification is one of the key processes that could change the properties and characteristics of spilled oil. It can affect other weathering processes and consequently the oil recovery operation. Mackay et al. (1980) provided a simulation of emulsification by using the incorporation rate of water into an oil slick:

$$
F W=K_{b}\left(1-\exp \left(\frac{-K_{a}}{K_{b}}(U+1)^{2} \times t\right)\right)
$$

where $F W$ is the fractional water content, $K_{a}$ is the cure fitting constant that varies with wind speed $\left(2 \times 10^{-6}\right), K_{b}$ is mousse viscosity constant ( 0.7 for crude oils and heavy fuel oil) ( $\mathrm{Za}$ deh and Hejazi, 2012), and $t$ is time (s).

Furthermore, the equation for the dispersion process is as follows (Mackay et al., 1980):

$$
F D=\frac{0.11 \times(U+1)^{2}}{1+50 \times \mu^{0.5} \times S T \times s_{t}}
$$

where $F D$ is the dispersion rate $\left(\mathrm{m}^{3} /\left(\mathrm{s} \cdot \mathrm{m}^{3}\right.\right.$ of oil $\left.)\right), \mu$ is the dynamic viscosity of the oil $(\mathrm{cP})$, and $S_{t}$ is the interface tension between oil and water (dyne $/ \mathrm{m})$.

When considering the simulation of the oil recovery efficiency, along with the weathering processes, the optimization model for oil skimming can be formulated as follows:

$\operatorname{Max} V=\sum_{s=1}^{N} S K_{i} \times O R R_{n i s}$

s.t.

$O R R_{n i s}=f_{O R R_{n i}}\left(\frac{V_{0}-\sum_{h=1}^{s-1}\left(V_{h}+F V_{h}+D V_{h}\right)}{A}\right)$

$F D_{s}=f_{F D}\left(S T_{s-1}\right)=f_{F D}\left(\frac{V_{0}-\sum_{h=1}^{s-1}\left(V_{h}+F V_{h}+D V_{h}\right)}{A}\right)$

$F V_{s}=F E_{s-1} \times\left(V_{0}-\sum_{h=1}^{s-1}\left(V_{h}+F V_{h}+D V_{h}\right)\right)$

$F W_{m}$

$=K_{b}\left(1-\exp \left(\frac{-K_{a}}{K_{b}}\right)(U+1)^{2} \times 3,600\right) \quad \forall m=2, \cdots, N$

$D V_{s}=F D_{s-1} \times\left(V_{0}-\sum_{h=1}^{s-1}\left(V_{h}+F V_{h}+D V_{h}\right)\right)$

$\sum_{j=1}^{n} A_{i j} S K_{j} \leq B_{i}, \quad i=1, \cdots, m$

$S K_{j} \geq 0$

where $F V$ is the evaporated oil $\left(\mathrm{m}^{3}\right)$ and $D V$ is the dispersed oil $\left(\mathrm{m}^{3}\right)$.

\subsection{Agent-Based Model for Device Interaction and Agent- Based Simulation-Optimization Coupling}

During offshore oil spill response, the interactions among different sectors (response devices, responders, decision makers, etc.) dynamically occur during the whole process of response. It may lead to unreliability or compromise of the response actions if these interactions are not considered in the global optimization. In order to address these interactions, an agent-based model is introduced.

As shown in Figure 1, an agent usually contains some basic properties as follows: (1) able to survive and respond to the environment; (2) able to dynamically receive the information from the local environment; (3) driven by certain goals or purposes; and (4) has certain intrinsic behaviors reacting with the environments and other agents (Liu, 2001).

The general algorithm of an agent-based model is shown as follows:

General algorithm of an agent-based model:

$$
\begin{aligned}
& t=1 \text { (initial state) } \\
& \text { while } t \leq t^{\max } \text { or } t \geq t^{\min } \text { (goal is not satisfied) do } \\
& \text { for Agent } i \quad \forall i=1: n \\
& \text { Reactive behaviours }\left(\mathbf{B}_{\mathbf{i}}\right) \leftarrow \text { Perceive envi } \\
& \text { ronmental information }\left(\mathbf{E}_{\mathbf{t}}\right)
\end{aligned}
$$




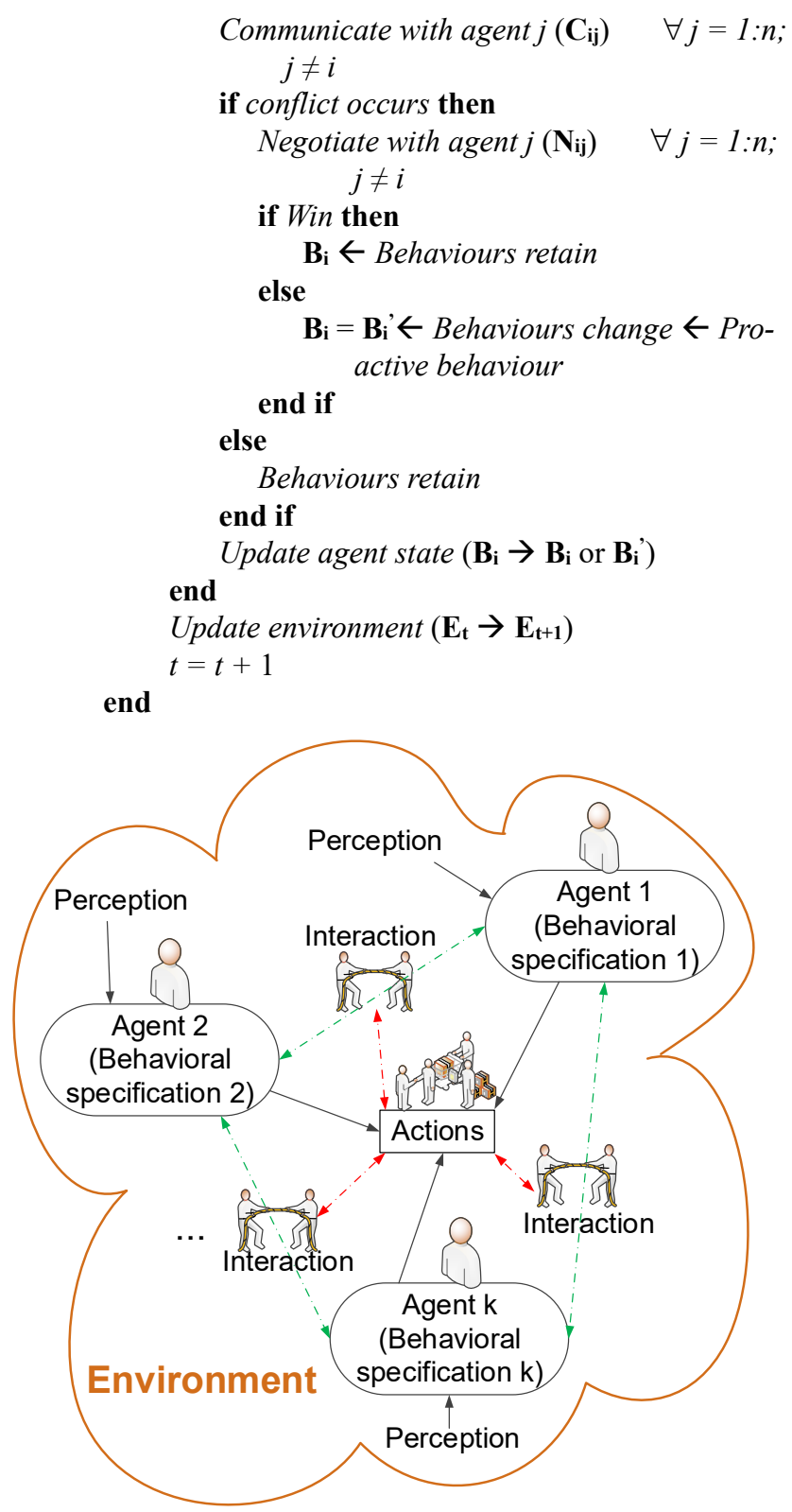

Figure 1. Basic structure of an agent-based model.

This agent model can be embedded in the DMINP approach as simulative constraints to reflect the dynamic interacttions of devices (e.g., ship mount devices) during offshore oil spill response, leading to an agent-based simulation-optimization coupling (ASO) approach. The framework of the ASO approach is shown in Figure 2. This approach can utilize the global objectives as the goals for agents and dynamically adjust the plan settings according to the agent-based modeling.

\section{Case Study}

\subsection{Background}

Consider an offshore spill of Statfjord oil with a total amount of $1,000 \mathrm{~m}^{3}$. Statfjord is a light, low sulphur crude oil produced from North Sea with an API of 39.5 (Statoil, 2010). Due to advection and spreading, the spilled oil was separated to 7 slicks within a $70 \mathrm{~km}$ by $30 \mathrm{~km}$ area. The volumes and locations of these oil slicks are shown in Table 1. The initial thickness of each slick is $50 \mathrm{~mm}$.

Three ships (Ship A, Ship B, and Ship C) with three types of ship mounted skimmers were applied in this area to collect the spilled oil. Each ship was located in a different harbor and required a specific period of time for allocation (Figure 3 ).

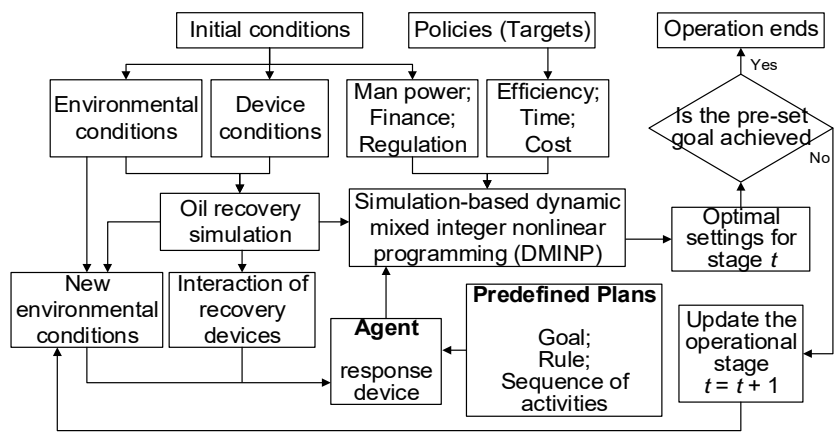

Figure 2. Framework of the agent-based simultion-optimization coupling (ASO) approach.

Table 1. Locations and Volumes of Oil Slicks

\begin{tabular}{|c|c|c|c|}
\hline \multirow{2}{*}{ Slick } & \multicolumn{2}{|c|}{ Location } & \multirow{2}{*}{ Oil volume $\left(\mathrm{m}^{3}\right)$} \\
\hline & $\mathrm{X}(\mathrm{km})$ & $\mathrm{Y}(\mathrm{km})$ & \\
\hline 1 & 24.03 & 10.03 & 132.44 \\
\hline 2 & 5.80 & 18.46 & 219.37 \\
\hline 3 & 19.97 & 20.99 & 146.69 \\
\hline 4 & 14.07 & 3.43 & 137.82 \\
\hline 5 & 27.49 & 5.42 & 81.07 \\
\hline 6 & 16.61 & 29.39 & 79.86 \\
\hline 7 & 3.27 & 13.84 & 202.76 \\
\hline
\end{tabular}

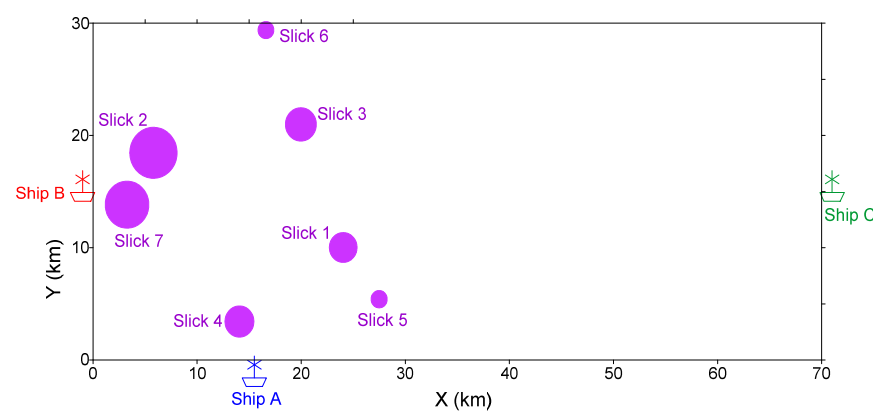

Figure 3. Locations of response ships and oil slicks.

\subsection{Oil Spill Skimming}

In order to determine their efficiencies, ORRs and ORES of these skimmers were collected from the previous tests conducted by Environmental Canada and OHMSETT (Schulze, 1998). According to the collected information, a series of $O R R_{n 1}, O R R_{n 2}$ and $O R R_{n 3}$ were generated based on calculating ORRs * OREs using different oil thickness with a viscosity of $1,000 \mathrm{cSt}$ (Schulze, 1998). Fittings were then applied based 
on quadratic functions to generate the regression models of $O R R_{n}$ with the change of spilled oil thickness, representing the recovery efficiencies of the three types of skimmers (Figure 4). Such a change of slick thickness is usually caused by the processes of spreading, shifting, weathering (e.g., evaporation, dispersion, dissolution, emulsification, etc.), as well as oil recovery. The details about the $O R R_{n}$ of the skimmers as well as the regression models of the efficiencies are shown in Table 2.

Table 2. Time of Devices Allocation and Model Parameters of ORRn (Li et al., 2012, 2014)

\begin{tabular}{lll}
\hline \multirow{2}{*}{ Types of skimmers } & \multicolumn{2}{l}{ Model parameter for ORR } \\
\cline { 2 - 3 } & $\mathrm{a}$ & $\mathrm{b}$ \\
\hline $\mathrm{SK}_{1}$ (Ship A) & 0.01437 & 0.01602 \\
$\mathrm{SK}_{2}$ (Ship B) & -0.00791 & 0.84975 \\
$\mathrm{SK}_{3}$ (Ship C) & -0.01591 & 1.54975 \\
\hline
\end{tabular}

Due to the challenge of transportation, no more skimmers and vessels can be supplied at this stage. The objective of the response in the current stage is to determine the allocations (routes) of ships to achieve $90 \%$ of oil recovery with a minimum time window. According the above information and the algorithms of DMINP and ASO, a global optimization model can be generated as follows:

$\operatorname{Min} T$

s.t.

$\sum_{t=1}^{T} T V_{t} \geq 0.9 \times 1000$

$T V_{t}=f_{t}\left(\right.$ Agent $\left._{i}, S T_{t k}\right) \forall t=1, \cdots, T ; i=1,2,3 ; k=1, \cdots, 7$ (16c)

where $T$ is the time window of operation (hour); $t$ is the indicator of stage; $T V$ is the recovered oil in each stage $\left(\mathrm{m}^{3}\right)$; and $f_{t}\left(\right.$ Agent $\left._{i}, S T_{t k}\right)$ is the function of the agent-based modeling at stage $t ; S T_{t k}$ is the slick thickness of each slick $k$ at stage $t$ (mm); and Agent is the referring to each skimmer mounted ship. The development of the agent function is as follows:

The agent-based model for offshore oil spill recovery:

$$
\begin{aligned}
& t=1 \text {; } S T_{l k}=50 \mathrm{~mm} \text {; initial location of ships }\left(\mathbf{L S}_{\mathbf{t i}}\right) ; \\
& \quad \text { speed of ships }(\mathbf{S S})=20 \mathrm{~km} / \mathrm{hour} \\
& \text { while } \sum_{t=1}^{T} T V_{t} \leq 0.9 \times 1000 \text { do } \\
& \quad \text { for Ship } i \quad \forall i=A, B, C
\end{aligned}
$$

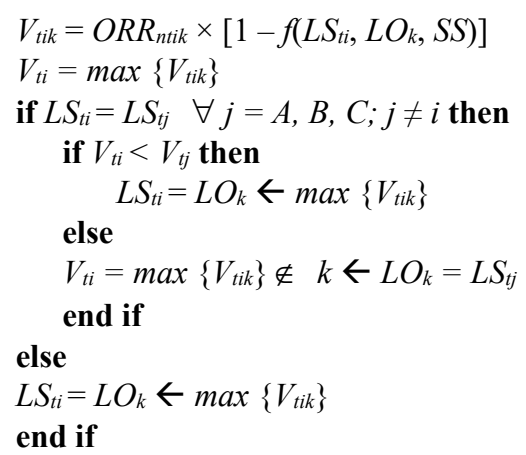

end

$T V_{t}=\sum_{i=A}^{C} V_{t i}, R V_{L S_{t i}}=R V_{t k}-V_{t i}$,

$S T_{t+1, L S_{i i}}=R V_{L S_{t i}} / I V_{L S_{t i}} \times 50 \leftarrow$ update environment

$\mathrm{LS}_{\mathrm{ti}} \leftarrow$ Update agent state

$t=t+1$

end

where $L S_{t i}$ is the location of ship $i$ at stage $t,(x, y)$; SS is the speed of ships (20 km/hour); $V_{t i k}$ is the potential oil recovery if ship $i$ removes from the current location to Slick $k$ at stage $t$, $\left(\mathrm{m}^{3}\right)$; $O R R_{\text {ntik }}$ is the function of net oil recovery rate if skimmer on ship $i$ operates on Slick $k$ at stage $t,\left(\mathrm{~m}^{3} /\right.$ hour $)$, the calculation of the corresponding $O R R_{n}$ is based on the Equation 8 and the values in Table $2 ; L O_{k}$ is the location of Slick $k$, $(x, y) ; V_{t i}$ is the maximum value of $V_{t i k},\left(\mathrm{~m}^{3}\right) ; R V$ is the remaining oil on each slick $\left(\mathrm{m}^{3}\right)$; and $I V$ is the initial volume of spilled oil on each oil slick $\left(\mathrm{m}^{3}\right)$.

\subsection{Oil Weathering}

In order to further test the feasibility of the ASO approach with oil weathering, three major weathering processes, evaporation, emulsification, and dispersion, is considered. The inputs for the oil weathering processes are shown in Table 3.

According to Fingas (2011), the empirical equation of evaporation for the Statfjord oil is as follows:

$F E=\frac{2.67+0.06 \times(T-273.15) \times \operatorname{Ln}(t)}{100}$

The simulation of oil dispersion is based on the Equation 14. Accordingly, the global optimization model can be generated as follows:

Table 3. Statjord Crude Oil Characteristics for the Weathering Processes of Evaporation and Dispersion (Nazir et al., 2008)

\begin{tabular}{llll}
\hline Parameter & Value & Parameter & Value \\
\hline Temperature $(\mathrm{T})$ & $298 \mathrm{~K}$ & Wind speed $(\mathrm{U})$ & $5 \mathrm{~m} / \mathrm{s}$ \\
Vapor pressure $\left(\mathrm{P}^{\mathrm{sat}}\right)$ & $10.4 \mathrm{~Pa}$ & Molecular weight $(\mathrm{M})$ & $128.2 \mathrm{~g} / \mathrm{mol}$ \\
Density of oil $\left(\rho^{\text {sat }}\right)$ & $832 \mathrm{~kg} / \mathrm{m}^{3}$ & Gas constant $(\mathrm{R})$ & $8.314 \mathrm{~m} \cdot \mathrm{Pa} / \mathrm{mol} \cdot \mathrm{K}$ \\
Viscosity of the oil $(\mu)$ & $3.03 \mathrm{cP}$ & Interface tension of oil and water $\left(\mathrm{S}_{\mathrm{t}}\right)$ & $2000 \mathrm{dyne} / \mathrm{m}$ \\
\hline
\end{tabular}




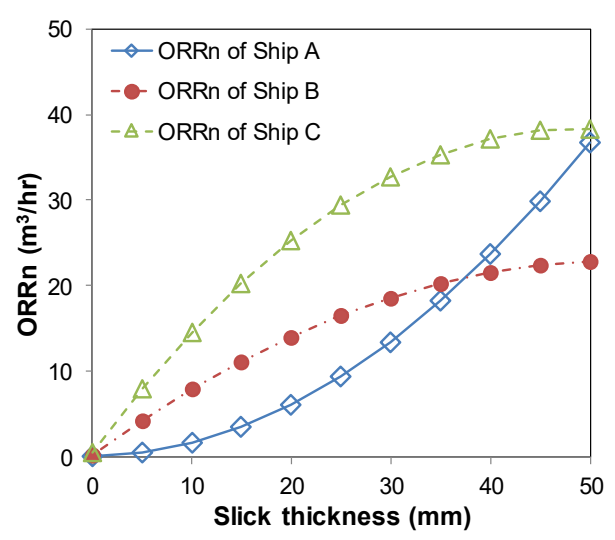

Figure 4. Net oil recovery rates for the skimmers (Schulze, 1998; Li et al., 2012, 2014).

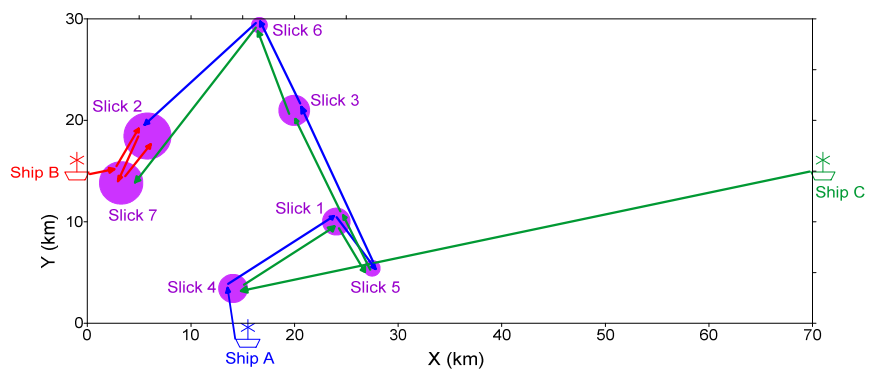

Figure 5. Optimal routes of the responding vessels based on ASO modeling.
Min T

s.t.

$\sum_{t=1}^{T} T V_{t} \geq 0.9 \times 1000$

$T V_{t}=f_{t}\left(\right.$ Agent $\left._{i}, S T_{t k}\right) \forall t=1, \cdots, T ; i=1,2,3 ; k=1, \cdots, 7$

$F E_{t k}=\frac{2.67+0.06 \times(T-273.15) \times \operatorname{Ln}(60)}{100}$

$F W_{t k}=K_{b}\left(1-\exp \left(\frac{-K_{a}}{K_{b}}\right)(U+1)^{2} \times 3,600\right)$

$F D_{t k}=\frac{0.11(U+1)^{2}}{1+50 \mu^{0.5}\left(\frac{I V_{k}-\sum_{h=1}^{t-1}\left(R V_{h k}+V F_{h k}+V D_{h k}\right)}{A_{k}}\right) S_{t}}$

$V F_{t}=\sum_{k=1}^{7} I V_{k} \times F E_{t k}$

$V D_{t}=\sum_{k=1}^{7} I V_{k} \times F D_{t k} \times 3,600$

Based on the assumptions that only the provided weathering processes will occur during an oil spill and no sedimentation will happen during the weathering, the corresponding ASO problem for offshore oil spill recovery can be finally formed and solved by programming software (i.e., MATLAB ${ }^{\circledR}$ with LINDO API ${ }^{\circledR}$ ).

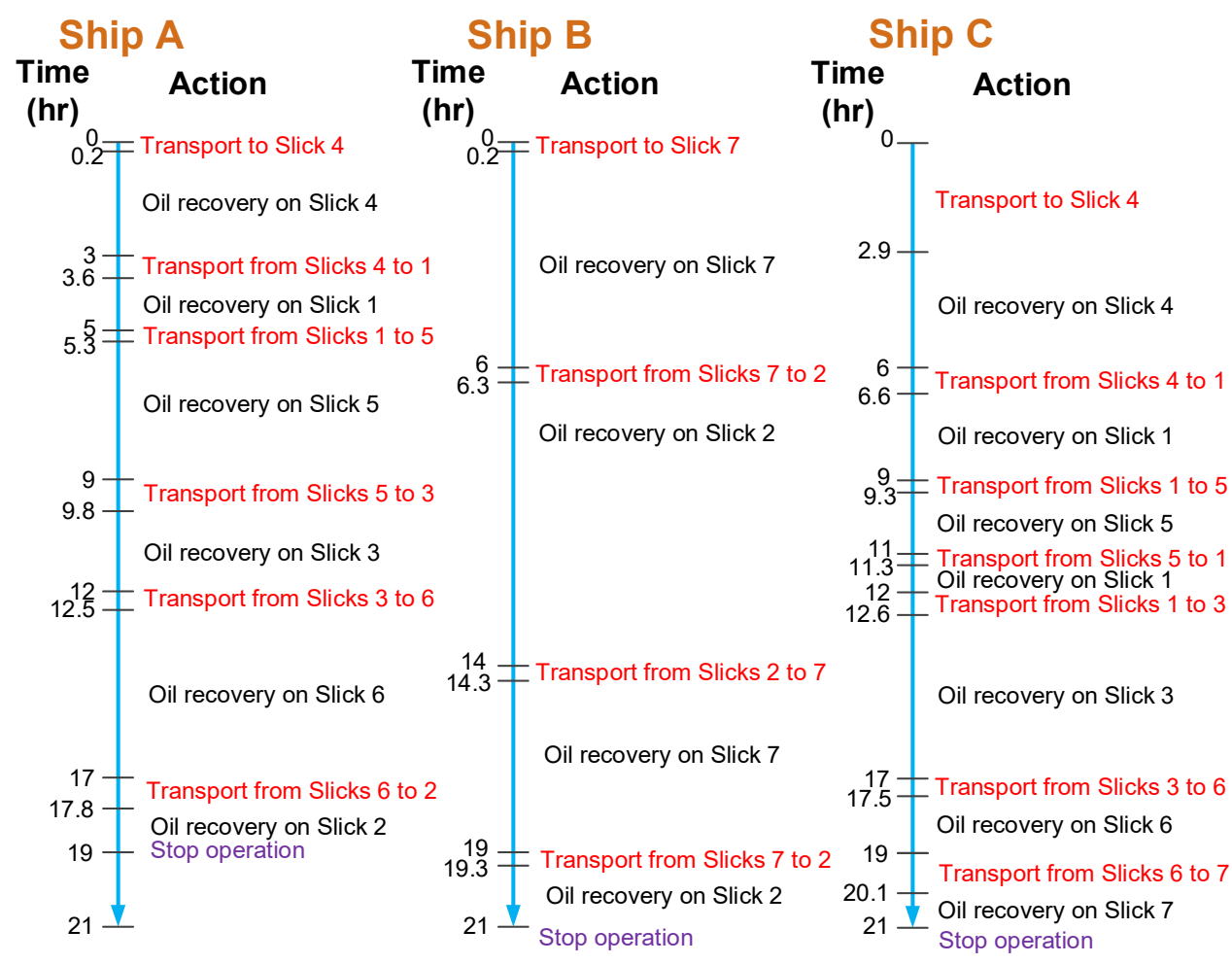

Figure 6. Detailed schedules of the responding vessels. 


\section{Results and Discussion}

\subsection{Modeling without Oil Weathering}

The modeling results indicated that, without considering the oil weathering processes, the time window for achieving an oil recovery rate of $90 \%$ was 21 hours based on the optimal vessel routes determined by the ASO modeling.

The routes of three responding vessels are shown in Figure 5 and the detailed schedule of each vessels are listed in Figure 6. Due the closest distances to two large slicks (Slicks 2 and 7) and stable relatively stable efficiency of oil recovery, Ship B with $\mathrm{SK}_{2}$ was mainly working on these two slicks. No interaction between Ship B and other two ships was identified until the late stage (after the $15^{\text {th }}$ hour). Furthermore, strong interactions were observed between Ships A and C. However, due to the long distance from Ship C to the slicks, it took 2.9 hours for this ship to arrive in the first slick. No oil recovery was made by this vessel at the first three hours and no interaction occur between Ships A and C. From the $3^{\text {rd }}$ to the $19^{\text {th }}$ hour, close interactions tool place between these two ships. Because the recovery efficiency of the skimmer on Ship C $\left(\mathrm{SK}_{3}\right)$ was high and had less significant decrease than the one on Ship B $\left(\mathrm{SK}_{1}\right)$ (Figure 4), the allocation of Ship A varied according to the allocation of Ship B. Since the distances were far from these two ships to Slicks 2 and 7, the interactions between Ships A and C occurred on Slicks 1 and 3-6. Due to the unacceptable decrease of recovery efficiency, Ship A stopped operation after the $19^{\text {th }}$ hour. Interactions of all three ships happened after the $17^{\text {th }}$ hour.

Figure 7 depicts the amount of oil recovered by each ship at each stage, while Figure 8 indicates the cumulative amount of recovered oil. Although the recovery amounts fluctuated during the whole operation period, the global trends of recovery decreased along with time. Due to the strong interactions between Ships A and C, the fluctuations of the amount of oil recovered by these two ships were more significant than that collected by Ship B. Furthermore, as controlled by the global objecttive, the overall oil recovery by all ships kept increasing until the ultimate goal was achieved.

In order to demonstrate the advantages of the ASO approach, a comparison was made between the ASO and the shortest distance optimization in offshore oil spill recovery. In the shortest distance modeling, the allocations of ships were only driven by the short distance between each ship and each oil slick. The ships left the slicks until $90 \%$ of oil recovery was achieved on each slick. The comparison results are illustrated in Figure 9. At the early stage (the $1^{\text {st }}$ to the $5^{\text {th }}$ stage), oil recovery efficiencies derived from the two approaches were almost the same. Since the $5^{\text {th }}$ stage, the recovery efficiency of the shortest distance approach became lower than the one based on the ASO. Furthermore, this inferiority became more significant along with time. To achieve the $90 \%$ oil recovery rate, the settings from the shortest distance required 23 hours while the settings from the ASO approach only required 21 hours.

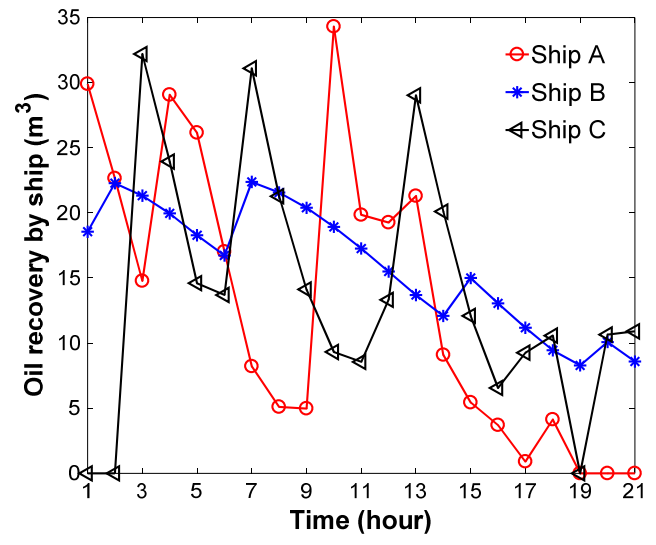

Figure 7. Oil recovery by each ship at each stage.

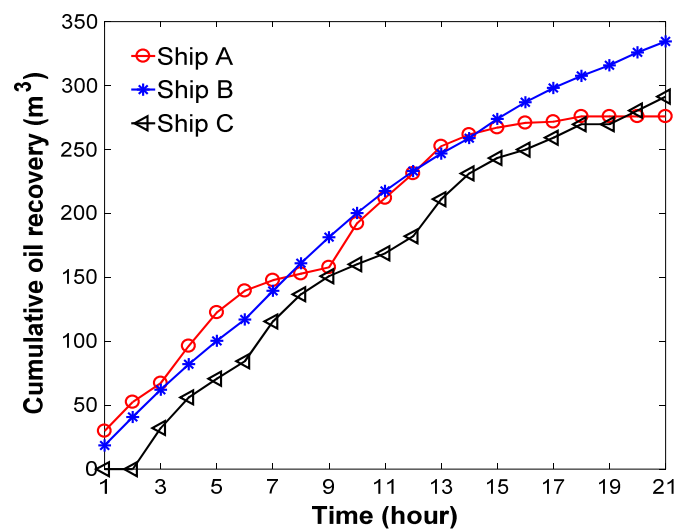

Figure 8. Cumulated oil recovery by each ship.

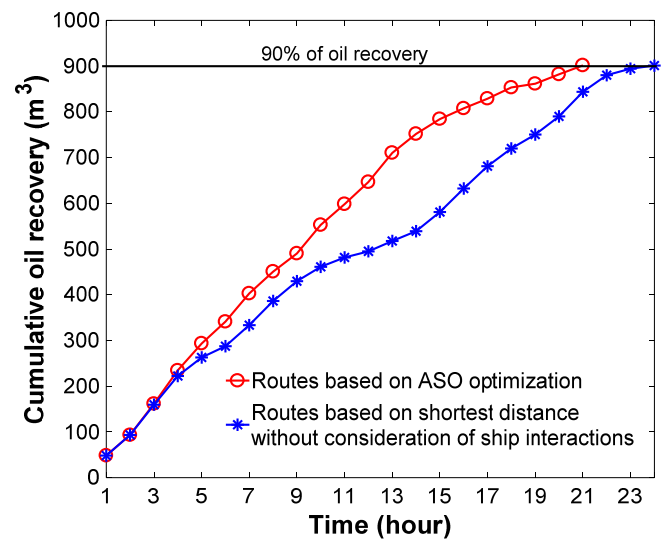

Figure 9. Comparison of oil recovery by ship routes determined by ASO and shortest distance.

\subsection{Modeling with Oil Weathering}

Based on the ASO model developed for oil recovery and the equations for evaporation, emulsification, and dispersion (Equation 18), the ASO model for oil recovery with weathering (evaporation, emulsification, and dispersion) was developped and solved. The modeling results indicated that, by considering the weathering processes, the time window for achi- 


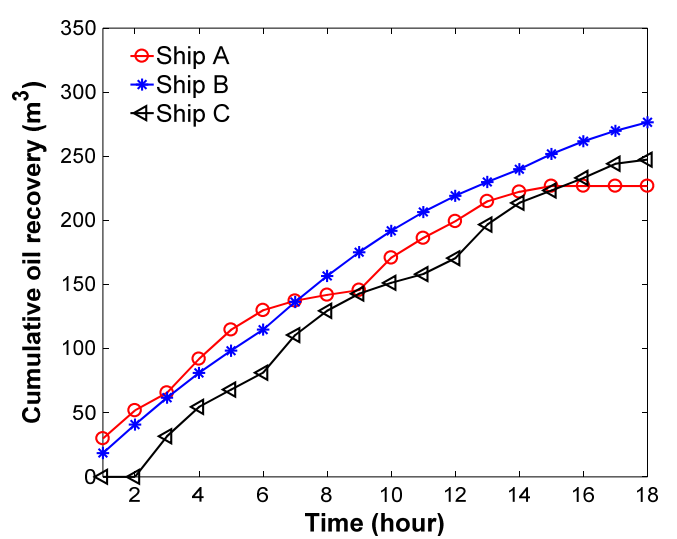

Figure 10. Cumulated oil recovery by each ship with oil weathering.

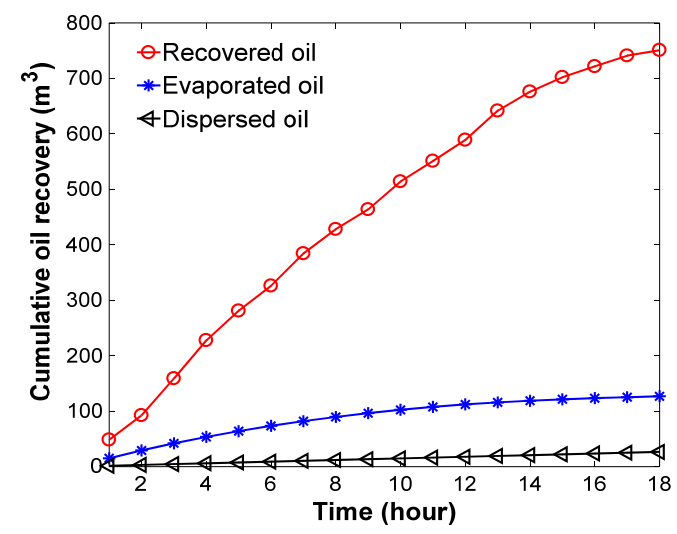

Figure 11. Transport and fate of spilled oil during the operational period.

eving the $90 \%$ oil recovery was 18 hours based on the optimal routes of responding vessels determined by the ASO approach.

The optimal routes and schedules of ships based on the ASO with consideration of weathering were similar to the ones not considering weathering. As shown in Figure 10, the amount of oil recovered by each ship was lower than the amount without weathering, which was caused by a $15 \%$ reduction of oil due to evaporation and dispersion (Figure 11). Furthermore, the increase trends of oil recovery were less significant. This is because the additional decrease of slick thickness (caused by evaporation and dispersion) further lowered the efficiencies of skimmers mounted on ships (Figure 4). Based on the ASO approach, the optimal routes of vessels had led to $75 \%$ oil recovery, $12 \%$ oil evaporation, and $3 \%$ oil dispersion.

\section{Conclusions}

An agent-based simulation-optimization (ASO) coupling approach has been developed to support oil recovery and device allocation during offshore oil spill responses, providing sound decisions for oil recovery in a fast and dynamic man- ner. The ASO approach was developed based on the integration of a global optimization approach, simulation-based dynamic mixed integer nonlinear programming (DMINP), and an agent-based model (ABM) for reflecting devices interactions. The DMINP approach converted the simulation model into constraints which were dynamically linked to the decision variables, and broke the time series into multiple stages according to controllable time intervals in practical manner. The ABM captured the interactions between components in offshore oil spill recovery systems and integrate with global optimization. Therefore, The ASO approach could provide sound decisions for oil recovery under highly interactive conditions and therefore improve recovery efficiency.

In the case study, the developed approach was applied to determine the allocation of 3 responding vessels from 7 different locations spilled oil slicks. The modeling results indicated that the optimal routes of vessels could lead to a minimum operational time window of 21 hours to achieve the $90 \%$ oil recovery rate, which was greatly improved from the traditional method that is based on the shortest distance ( 23 hour). This demonstrates the superiority of the ASO approach. The feasibility of the ASO approach in being integrated with other simulation processes (e.g., weathering process) was also tested with the consideration of evaporation and dispersion processes. The results demonstrate that the proposed approach can timely and effectively support optimal allocation of devices and control of operation under dynamic conditions and improve recovery efficiency.

The results of case study have proved the feasibility of the proposed ASO approach in supporting the oil recovery by skimming. Extensively, the ASO approach is also capable to dynamically support the whole process of oil recovery oil, including the devices allocation, deployment, and operation of containment, skimming, surfactant utilization, in-situ burning, etc.

In future studies, hydrodynamic simulation and more weathering processes will be considered to further test the feasibility and capability of the developed ASO approach. Future research efforts may also include the consideration of possibilistic uncertainties for incorporating expert knowledge into the decision making process of offshore oil spill responses. Testing of the developed method through real-world applications is undergoing with the collaboration with local oil spill responders.

Acknowledgments. This study was funded by Natural Sciences and Engineering Research Council of Canada (NSERC), Research \& Development Corporation (RDC) of Newfoundland and Labrador, and Canada Foundation for Innovation (CFI). Special thanks go to Fisheries and Oceans Canada (DFO), Eastern Canada Response Corporation (ECRC), and Canadian Coast Guard (CCG) for their advice.

\section{References}

Atlas, R.M., and Hazen, T.C. (2011). Oil biodegradation and bioremediation: a tale of the two worst spills in US history. Environ. Sci. Technol., 45(16), 6709-6715. http://dx.doi.org/10. 1021/es20 13227 
Baruque, B., Corchado, E., Mata, A., and Corchado, J.M. (2010). A forecasting solution to the oil spill problem based on a hybrid intelligent system. Info. Sci., 180(10), 2029-2043. http://dx.doi. org/10.1016/j.ins.2009.12.032

Ben-Awuah, E., Elkington, T., Askari-Nasab, H., and Blanchfield, F. (2015). Simultaneous production scheduling and waste management optimization for an oil sands application. J. Environ. Inf., 26(2), 80-90. http://dx.doi.org/ 10.3808/jei.201500305

Bjerkemo, O.K. (2011). Behaviour of oil and HNS spilled in arctic waters - an arctic council project. Proc. of the International Oil Spill Conference (IOSC), http://dx.doi.org/10.7901/2169-33582011-1-229

Brandvik, P.J, Sørheim, K.R., Singsaas, I., and Reed, M. (2006). Short State-of-the-Art Report on Oil Spills in Ice-Infested Waters, Sintef report A 06148, Trondheim, Norway.

Brebbia, C.A. (2001). Oil Spill Modeling and Processes, WIT Press, UK.

Cai, Y.P., Huang, G.H., Tan, Q., and Yang Z.F. (2009). Planning of community-scale renewable energy management systems in a mixed stochastic and fuzzy environment. Renewable Energy, 34(7), 1833-1847. http://dx.doi.org/10.1016/j.renene.2008.11.024

Chen, W.T., Li, Y.P., Huang, G.H., Chen, X., and Li, Y.F. (2010). A two-stage inexact-stochastic programming model for planning carbon dioxide emission trading under uncertainty. Appl. Energy, 87(3), 1033-1047. http://dx.doi.org/10.1016/j.apenergy.2009.09. 016

Cheng, S., Chan, C.W., and Huang, G.H. (2002). Using multiple criteria decision analysis for supporting decisions of solid waste management. J. Environ. Sci. Health, Pt. A: Toxic/Hazard. Subst. Environ. Eng., 37(6), 975-990. http://dx.doi.org/10.1081/ ESE-12 0004517

Fingas, M.F. (2010). Oil Spill Science and Technology, WileyBlackwell. Mississauga, Ontario, Canada.

Fingas, M.F. (2011). Oil Spill Science and Technology: Prevention, Response, and Cleanup, Elsevier/Gulf Professional Pub, pp. 1156.

Gill, D.A., Picou, J.S., and Ritchie, L.A. (2012). The Exxon Valdez and BP oil spills a comparison of initial social and psychological impacts. Am. Behav. Sci., 56(1), 3-23. http://dx.doi.org/10.1177/ 0002764211408585

Gong, W., Duan, Q.Y., Li, J.D., Wang, C., Di, Z.H., Ye, A.Z., Miao, C.Y., and Dai, Y.J. (2016). An intercomparison of sampling methods for uncertainty quantification of environmental dynamic models. J. Environ. Inf., 28(1), 11-24. http://dx.doi.org/10.3808/ jei.201500310

Griggs, J.W. (2011). BP gulf of Mexico oil spill. Energy Law J., 32(1). 57-79.

Gundlach, E.R., and Hayes, M.O. (1978). Vulnerability of coastal environments to oil spill impacts. Mar. Technol. Soc. J., 12(4)18-27.

Huang, G.H., Cohen, S.J., Yin, Y.Y., and Bass, B. (1996). Incorporation of inexact dynamic optimization with fuzzy relation analysis or integrated climate change impact study. J. Environ. Manage., 48(1), 45-68. http://dx.doi.org/10.1006/jema.1996.0065

Huang, G.H., and Cao, M.F. (2011). Analysis of solution methods for interval linear programming. J. Environ. Inf., 17(2), 54-64. http:// dx.doi.org/10.3808/jei.201100187

Huang W., Baetz B.W., and Razavi, S. (2016). A GIS-based integer programming approach for the location of solid waste collection depots. J. Environ. Inf., 28(1), 39-44. http://dx.doi.org/10.3808/jei. 201600342

Jing, L., Chen, B., Zhang, B.Y., and Li, P. (2012). A stochastic simulation-based hybrid interval fuzzy programming approach for optimizing the treatment of recovered oily water. J. Ocean Technol., 7(4), 59-72.

Kokkonen, T., Ihaksi, T., Jolma, A., and Kuikka, S. (2010). Dynamic mapping of nature values to support prioritization of coastal oil combating. Environ. Model. Software, 25(2), 248-257. http://dx.doi. org/10.1016/j.envsoft.2009.07.017

Korotenko, K., Mamedov, R.M., Mooers, C.N.K. (2000). Prediction of the dispersal of oil transport in the Caspian Sea resulting from a continuous release. Spill Sci. Technol. Bull., 6(5-6), 323-339. http://dx.doi.org/10.1016/S1353-2561(01)00050-0

Krohling, R.A., and Campanharo, V.C. (2011). Fuzzy TOPSIS for group decision making: A case study for accidents with oil spill in the sea. Expert Syst. Appl., 38(4), 4190-4197. http://dx.doi.org/10. 1016/j.eswa.2010.09.081

Li, P., Chen, B., Zhang, B.Y., Jing, L., and Zheng, J.S. (2012). A multiple-stage simulation-based mixed integer nonlinear programming approach for supporting offshore oil spill recovery with weathering processes. J. Ocean Technol., 7(4), 87-105.

Li, P., Chen, B., Zhang, B.Y., Liang, J., and Zheng, J.S. (2014). Monte Carlo simulation-based dynamic mixed integer nonlinear programming for supporting oil recovery and devices allocation during offshore oil spill responses. Ocean Coast. Manage., 89, 58-70. http://dx.doi.org/10.1016/j.ocecoaman.2013.12.006

Liu, J.M. (2001). Autonomous Agents and Multi-Agent Systems: Explorations in Learning, Self-Organization, and Adaptive Computation. Singapore: World Scientific, 2001. http://dx.doi.org/10. $1142 / 4399$

Liu, J.M., Jing, H., and Tang, Y.Y. (2002). Multi-agent oriented constraint satisfaction. Artif. Intell., 136(1), 101-144. http://dx.doi.org/ 10.1016/S0004-3702(01)00174-6

Lv, Y., Huang, G.H., Li, Y.P., Yang, Z.F., Liu Y., and Cheng, G.H. (2010). Planning regional water resources system using an interval fuzzy bi-level programming method. J. Environ. Inf., 16(2), 43-56. http://doi.org/10.3808/jei.201000177

Mackay, D., Buist, I.A., Mascarenhas, R., and Paterson, S. (1980). Oil spill Processes and Models, Department of Chemical Engineering, University of Toronto, Environmental Service Publication No. EE-8. Toronto, Ontario.

Nazir, M., Khan, F., Amuotte, P., and Sadiq, R. (2008). Multimedia fate of oil spills in a marine environment - an integrated modeling approach. Process Saf. Environ. Prot., 86(2), 141-148. http://dx. doi.org/10.1016/j.psep.2007.10.002

Nourani, V., Khanghah, T.R., and Baghanam, A.H. (2015). Application of entropy concept for input selection of Wavelet-ANN based rainfall-runoff modeling. J. Environ. Inf., 26(1), 52-70. http://dx. doi.org/10.3808/jei.201500309

Picou, J.S. (2009). When the solution becomes the problem: The impacts of adversarial litigation on survivors of the Exxon Valdez oil spill. Thomas Law J., 7(1), 68-88.

Rahmani, M.A., and Zarghami, M. (2015). The use of statistical weather generator, hybrid data driven and system dynamics models for water resources management under climate change. J. Environ. Inf., 25(1), 23-35. http://dx.doi.org/10.3808/jei.201400285

Reed, M., Johansen, Ø., Brandvik, P.J., Daling, P., Lewis, A., Fiocco, R., Mackay, D., and Prentki, R. (1999). Oil spill modeling towards the close of the 20th century: overview of the state of the art. Spill Sci. Technol. Bull., 5(1), 3-16. http://dx.doi.org/10.1016/ S1353-2561(98)00029-2

Rege, S., Arenz, M., Marvuglia, A., Vázquez-Rowe, I., Benetto, E., Igos, E., and Koster, D. (2015). Quantification of agricultural land use changes in Consequential Life Cycle Assessment using mathematical programming models following a partial equilibrium approach. J. Environ. Inf., 26(2), 121-139.

Schulze, R. (1998). Oil spill response performance of skimmers. American Society for Testing and Materials, West Conshohocken, pp. 141. http://dx.doi.org/10.1520/mnl34-eb

Sheu, J.B., Chen, Y.H., and Lan, L.W. (2005). A novel model for quick response to disaster relief distribution. Proc. of the Eastern 
Asia Society for Transportation Studies.

Statoil (2010). CRUDE OIL ASSAY-Statfjord Blend. Product Technology and Customer Service, Statoil.

Tan, X., Xia, X.L., Li, S.Y., and Zhang, Q.F. (2015). Water quality characteristics and integrated assessment based on multistep correlation analysis in the Danjiangkou Reservoir, China. J. Environ. Inf., 25(1), 60-70. http://dx.doi.org/10.3808/jei.201500296

Verma, M., Gendreau, M., and Laporte, G. (2013). Optimal location and capability of oil-spill response facilities for the south coast of Newfoundland. Omega, 41(5), 856-867. http://dx.doi.org/10.1016/ j.omega.2012.10.007

Wooldridge, M., and Jennings, N.R. (1995). Intelligent agents: theory and practice. Knowl. Eng. Rev., 10(2), 115-152. http://dx.doi.org/ $10.1017 / \mathrm{S} 0269888900008122$

Yin, Y.Y., Huang, G.H., and Hipel, K.W. (1999). Fuzzy relation analysis for multicriteria water resources management. J. Water Resour. Plann. Manage., 125(1), 41-47. http://dx.doi.org/10.1061/(ASCE) 0733-9496(1999)125:1(41)

You, F., and Leyffer, S. (2011). Mixed-integer dynamic optimization for oil-spill response planning with integration of a dynamic oil weathering model. AICHE J., 57(12), 3555-3564. http://dx.doi.org /10.1002/aic. 12536

Zadeh, E.S., and Hejazi, K. (2012). Eulerian oil spills model using finite-volume method with moving boundary and wet-dry fronts. Model. Simul. Eng., 2012(2012). http://dx.doi.org/10.1155/2012/ 398387

Zhong, Z., and You, F. (2011). Oil spill response planning with consideration of physicochemical evolution of the oil slick: A multiobjective optimization approach. Comput. Chem. Eng., 35(8), 1614-1630. http://dx.doi.org/10.1016/j.compchemeng.2011.01.009 